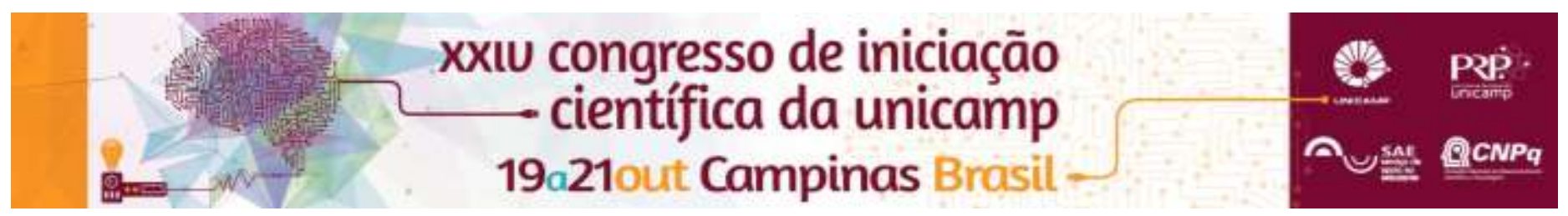

\title{
Virtual and plaster models for using in Dental Anatomy teaching.
}

Stella M. N. Hernandes, Gabrielly M. Costa*, Carolina A. Assef, Lyvia R. R. G. Hamparian, Alexandre R. Freire, Cristiano Manoel, Felippe B. Prado, Ana Cláudia Rossi.

\section{Abstract}

This study presented the models (3D and plaster model) of the human tooth, lower incisors), created to teaching Dental Anatomy in Odontology graduation course.

\section{Key words:}

morphology, dental anatomy, anatomy.

\section{Introduction}

In Odontology, learning of Dental Anatomy is the basis for the performance of the student in clinical activities. The teaching in the Universities has evolved with the introduction of digital tools that enable three-dimensional understanding of craniofacial and dental anatomy ${ }^{1}$.

The aim of this study was create a three-dimensional (3D) model and plaster models of the human lower incisors teeth to assist the dental anatomy classes.

\section{Results and Discussion}

The models of the teeth were constructed in four stages: an anatomical study on Atlas of Anatomy, and textbooks; reproducing teeth plaster and custom painting of the main anatomical structures; customized training in 3D modeling applied to biological structures; and construction of the virtual model in specific software for 3D modeling. The lower incisors modeling activity for learning the shape and dental structures was performed in Mimics v. 18.0 software (Materialise, Belgica).

We verified that the interaction with the three-dimensional environment allows students to view dental anatomical structures, for example, on any view, move around within it, and interact with their virtual objects, all in real time.

The Image 1 shows the 3D model of the lower central incisor, which will be used in theoretical undergraduate classes of Dental Anatomy to assist in the teaching and study.

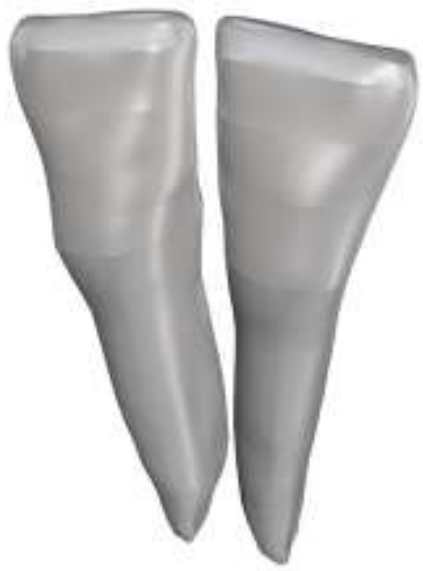

Image 1. 3D model created in Mimics v. 18.0 software (Materialise, Belgica) in buccal view.

\section{Conclusions}

The construction of tridimensional and plaster models contributed not only to the consolidation of learning by the students, but also the use of these models as teaching in Dental Anatomy classes.

\section{Acknowledgement}

The authors are grateful to the National Counsel of Technological and Scientific Development (PIBIC-EM$\mathrm{CNPq}$ ) for financial support.

${ }^{1}$ Sun, W.; Starly, B.; Nam, J.; Darling, A. Comput Aided Design. 2005, 37, 1097-1114. 